\title{
VENEZOLANOS EN ARGENTINA, ESTADOS UNIDOS Y PORTUGAL: UNA DIÁSPORA EN CONSTRUCCIÓN
}

\author{
Venezuelans in Argentina, the United States and Portugal: \\ a diaspora on the making?
}

\author{
Beatriz Padilla* \\ Magdalena López ${ }^{* * * *}$
}

\begin{abstract}
Resumen. En este artículo proponemos que la reciente migración venezolana es una diáspora en proceso de construcción. A partir de observación participante y entrevistas con informantes clave e inmigrantes venezolanos residentes en Argentina, Estados Unidos (Florida) y Portugal, sostenemos que tanto la experiencia común de la crisis humanitaria en el país de origen como la realidad transnacional compartida, contribuye a que los venezolanos en el exterior constituyan una diáspora en proceso de institucionalización y consolidación.
\end{abstract}

Palabras clave: inmigración venezolana; transnacionalismo; diáspora; crisis humanitaria.

\begin{abstract}
In this article, we argue that recent Venezuelan migration is a diaspora on the making. Based on participant observations and interviews with key informants and Venezuelan immigrants living in Argentina, the United States (Florida), and Portugal, we establish that the shared experience arising from the humanitarian crisis in their country of origin, and their common transnational reality is contributing to the process institutionalization and consolidation of the Venezuelan diaspora.
\end{abstract}

Keywords: Venezuelan migration; transnationalism; diaspora; humanitarian crisis.

\section{Introducción}

El concepto de diáspora es muy antiguo, sin embargo, el entendimiento y aplicación del mismo ha cambiado mucho en los últimos tiempos, adaptándose tanto a los fenómenos migratorios como a la forma de entenderlos desde un

\footnotetext{
University of South Florida. Tampa, FL, USA. E-mail: padilla.beatriz@gmail.com. Orcid: https:// orcid.org/0000-0002-2359-3369.

** Kellogg Institute for International Studies, University of Notre Dame, USA.

${ }^{* * *}$ Instituto Universitário de Lisboa (ISCTE-IUL), Centro de Estudos Internacionais, Lisboa, Portugal. E-mail: mlopez23@nd.edu. Orcid: https://orcid.org/0000-0003-1446-9179.
} 
punto de vista teórico, práctico y metodológico. En este sentido, hablar de la inmigración en sí no es hablar de diáspora, sino que es necesario reflexionar sobre un fenómeno de movilidad para poder pensar en la diáspora. El caso de Venezuela y de los venezolanos esparcidos por el mundo, resulta de interés ya que además de ser una realidad actual, permite poner en diálogo el concepto de diáspora con el de transnacionalismo y, al mismo tiempo, identificar algunas de sus características, al menos en el presente, cuando este pueblo atraviesa una crisis humanitaria, migratoria y sanitaria. Este ejercicio de reflexión puede así contribuir a un mejor y más actualizado entendimiento de la diáspora, y es el objetivo del presente artículo. Para ello reflexionamos sobre el trabajo de campo realizado en tres países de destino de la migración venezolana, Portugal, Argentina y Estados Unidos, mapeando motivaciones, justificaciones y políticas migratorias que han impactado en dicha movilidad, analizándola de forma comparada.

\section{Éxodo masivo y crisis humanitaria compleja}

Desde el año 2015 Venezuela vive una crisis humanitaria compleja que ha causado una masiva "migración forzada" (WOLA, 2020; HRW, 2019; OAS/CIDH, 2018) sin precedentes en la historia contemporánea de ese país. A la fecha de hoy ACNUR estima que cerca de seis millones de venezolanos han abandonado Venezuela en los últimos años (2021b). Para tener idea de las dimensiones de este éxodo migratorio, se estima que los venezolanos superarán en número a los refugiados sirios a fines del año 2021 (Smolansky, 2020). Estamos, además, ante un fenómeno que no parece tener fin en un futuro cercano y que ni siquiera se ha visto significantemente disminuido tras el cierre de fronteras debido a la pandemia de la Covid-19.

El término de "crisis humanitaria compleja" alude a una situación en la que todos los órdenes de la vida cotidiana se ven desestructurados por diversas causas políticas económicas y socio-culturales (HRW, 2019). Algunos estudiosos coinciden en sostener que la implantación forzada del modelo del "socialismo del siglo XXI" en 2007' la caída de los precios del petróleo y la transición de un régimen autoritario competitivo a una autocracia abierta en 2015, han conducido a la depreciación de las condiciones vida y la desinstitucionalización estatal (Gandini, Prieto, Lozano, 2019; Freitez, 2019, 2018; Dekocker, 2018). Asimismo, las sanciones y bloqueo económico internacional a partir del 2019, han ahondando la crisis sin que la exuberancia de los recursos naturales de Venezuela pueda ayudar a paliar la actual situación (CELAG, 2021). Así, Venezuela pasó de ser históricamente un país receptor de inmigrantes a uno emisor de emigrantes.

\footnotetext{
La reforma a la Constitución de 1999 para aplicar el llamado Plan Socialista fue rechazada en un referéndum de 2007. Aún así, Hugo Chávez avanzó con su proyecto al año siguiente mediante una ley habilitante.
} 
A pesar de que el actual régimen venezolano no suministra datos oficiales, el escenario nacional es innegable: hay una aguda escasez de alimentos, medicinas, gasolina, productos de higiene y de todo tipo de insumos, a la par que han colapsado los servicios públicos de salud y educación, así como del suministro de agua, electricidad e incluso internet. La Encuesta de Condiciones de Vida (Encovi) en 2018 arroja que el 91\% de la población venezolana vive en condiciones de pobreza (2019). De estos hogares pobres, $67 \%$ se encuentran en pobreza extrema. Anitza Freitez (2019) detalla la situación de esta manera:

La edición de 2017 de la Encovi, mostraba que ocho de cada diez hogares se encontraban en condiciones de inseguridad alimentaria, que ese año se produjeron más de 5.000 defunciones de niños menores de un año que se pudieron haber evitado o que la población ha perdido en promedio 3,5 años de esperanza de vida desde el 2017.

Este escenario está enmarcado en un clima de alta conflictividad y violencia, de ausencia de libertades políticas y civiles y de un proceso hiperinflacionario -el mayor que se conozca en el continente- (Freitez, 2019; Serbin, 2018).

Esta realidad de crisis humanitaria compleja constituye el escenario de la migración forzada venezolana y explica su gran heterogeneidad social. Aún cuando la migración venezolana se sigue caracterizando por su alto nivel de escolaridad - un poco más del tercio tienen formación universitaria, y la clase media y media alta conforman un 50,3\% del total de emigrantes (Freitez, 2019) - ; a partir del 2017, los estratos sociales más bajos se han ido sumando para conformar alrededor de un 26\% (Freitez, 2019) de la emigración total. De este modo, acudimos a una diversificación en la que se han ido incorporando los sectores más vulnerables por su falta de recursos. El número de mujeres embarazadas sin control prenatal, de personas con enfermedades crónicas - cáncer, diabetes, hipertensión, alteración de la salud mental, enfermedades del corazón- y de las que padecen de enfermedades contagiosas - $\mathrm{VIH}$, tuberculosis, enfermedades de transmisión sexual- (Edson Louidor, 2018), es cada vez mayor debido a la necesidad imperiosa de atención y controles médicos que no reciben en Venezuela. Hoy en día los migrantes venezolanos se desplazan no sólo por aire, sino cada vez más por tierra y mar, produciéndose fenómenos como el de los llamados "caminantes" y "balseros" venezolanos.

Este éxodo masivo ha desbordado muchas veces la capacidad de respuesta de los países latinoamericanos y está teniendo un severo impacto en la región. Tratándose en muchos casos de localidades y países que no estaban preparados para recibir tal contingente de personas, se han producido diversos episodios de xenofobia cuyos imaginarios a menudo alcanzan los medios de comunicación, fragilizándose aún más las posibilidades de los migrantes venezolanos de acceder a derechos básicos como el del trabajo, la salud y la educación. A este respecto, ha sido particularmente complicada la situación en aquellas poblaciones limítrofes de Colombia y Brasil que además de no estar preparadas para acoger tal volumen 
demográfico, son zonas fronterizas con su propia fragilidad. En 2018, por ejemplo, la población local de Pacaraima, en el estado de Roraima al norte del Brasil, quemó varias pertenencias de los inmigrantes venezolanos.

Tanto las condiciones de partida como las de tránsito y llegada a los países de destino suponen distintos obstáculos para los que migran. Tal como establecen Luciana Gandini, Victoria Prieto y Fernando Lozano, a diferencia de la mayoría de los flujos migratorios, los venezolanos han ido perdiendo el derecho a la identidad; esto es, se han visto sometidos a la imposibilidad de acceder a documentos de identificación como los pasaportes y las cédulas de identidad (2019). Efectivamente, hace ya varios años que el suministro de documentos y/o la renovación de los documentos de identificación no está garantizado por el régimen venezolano ni dentro ni fuera del país, debido a que las oficinas locales e instancias automatizadas no ofrecen servicio de manera regular, hay escasez de materiales como el papel, son cada vez menos las representaciones diplomáticas, y, desde el 2019, la oficialidad de algunas representaciones ha sido cuestionada por los gobierno de los países donde se encuentran, o porque existen dos representaciones, una del régimen de Maduro y otra de Guaidó. Así el estado de origen no brinda protección ni asegura la identidad de sus nacionales, colocando a muchos migrantes en una gran vulnerabilidad jurídica y negando el derecho de abandonar el país.

A la carencia de documentos se une una política nacional de desconocer la emigración venezolana. Freitez llama la atención sobre cómo la actualización de las políticas migratorias venezolanas en el año 2000 se enfocó sólo en la recepción de inmigrantes (2019). Durante los gobiernos de Hugo Chávez no se hizo ningún "reconocimiento público de la emigración de venezolanos a otros países" (Freitez, 2019). Cabe destacar que bajo el gobierno de Maduro, en cambio, sí se han hecho varias menciones al fenómeno emigratorio, casi siempre en términos peyorativos ${ }^{2}$. Esta situación es clave para entender la diáspora venezolana hoy.

En mayo del 2020, Maduro acusó al presidente colombiano de tener un plan de infectar de Covid-19 al país por medio de los venezolanos que deseaban regresar. A su vez, el secretario de gobierno del estado limítrofe del Zulia declaró que los retornados eran "armas biológicas" enviadas por Colombia para contaminar a Venezuela (López Maya, 2020). Esto no ha impedido, sin embargo, el uso publicitario por parte del régimen, del plan de repatriación Vuelta a la Patria en el que se calcula una movilización de 8.116 personas en 2020; es decir mucho menos de un $1 \%$ de la migración total. Muy probablemente, como sugiere Freitez, el reconocimiento de la migración forzada venezolana y las consecuentes políticas nacionales que debían implementarse, implicarían un reconocimiento de que "el

\footnotetext{
2 Sobre los migrantes venezolanos Freitez ahonda "Se ignora su existencia, se desdeña su relevancia y se desdeñan sus derechos fundamentales cuando se les restringe el derecho al sufragio o se levantan barreras para la tramitación de documentos de identidad (...) o la legalización de los documentos requeridos para emigrar" (2019).
} 
modelo político y económico que se ha querido implantar genera emigrantes" (2019). Sin embargo, también es una realidad causada por la situación de crisis sanitaria internacional, que alrededor de unos 140.000 venezolanos han vuelto a su país porque no han encontrado otra solución durante la huida en contexto de la pandemia.

Por otro lado, la migración venezolana ha implicado un desafío para países que históricamente no han sido receptores masivos de inmigrantes como Colombia, Ecuador, Perú y Chile. De hecho, ACNUR calcula 1,7 millones de migrantes venezolanos en Colombia, convirtiendo a ese país en el primer lugar de destino ${ }^{3}$ (2021b). Perú, Chile y Ecuador también figuran como lugares de preferencia, pero la lista de países en las Américas es mucho más extensa - las islas de Aruba, Curazao, Bonaire y Trinidad, Argentina, Brasil, Costa Rica, México, Panamá, Paraguay, Uruguay, la República Dominicana, Canadá y los Estados Unidos-; y comprende también a Europa - España, Italia y Portugal, principalmente - (IOM, 2018).

Las respuestas de los Estados han variado y van desde la improvisación, la puesta en práctica de medidas excepcionales y algunas respuestas más institucionalizadas y de largo plazo (Freitez, 2011). Nastassja Rojas sugiere que hubo una respuesta tardía por parte de varios países que creyeron inicialmente que la migración venezolana se limitaría a sectores de clase media y alta que se desplazaban con suficientes recursos y aportaban sus propios capitales a los países de acogida (2021). Por otro lado, Freitez llama la atención sobre algunos marcos jurídicos heredados de períodos dictatoriales en Chile, Perú, Ecuador y la República Dominicana basados en doctrinas de seguridad nacional (2019). En tales marcos se tiende a abordar la situación desde una lógica criminalizadora que no toma en cuenta la dimensión de los derechos humanos de los migrantes. La deportación expedita de colombianos y venezolanos en febrero de 2021 efectuada por el gobierno chileno es un ejemplo de este tipo de posicionamientos punitivos (Llorente, 2021; Méndez, 2021) que incluso fue incoherente con su política anterior de otorgar visas a los venezolanos.

No hay que olvidar tampoco que la dimensión política e ideológica de la crisis venezolana la ha vuelto susceptible de manipulación política dentro de las dinámicas domésticas de cada país receptor. Tal como establece Jefferson Díaz "Venezuela se ha convertido en chivo expiatorio de la política en América Latina" (2021). Así, por ejemplo, con fines electorales, se ha creado una matriz de opinión desfavorable a la migración venezolana en Ecuador y en Colombia ${ }^{4}$ por parte de

\footnotetext{
Hasta el 2015 era Estados Unidos.

4 Véanse la criminalización de los migrantes venezolanos por parte de del candidato Pedro Castillo en Perú; de la alcaldesa de Bogotá, Claudia López; de Paul Carrasco, candidato de oposición en Ecuador, e incluso de personeros del gobierno de Lenin Moreno en ese país (Carrasco, 2021; Díaz, 2021).
} 
candidatos nacionales y locales, mientras que anteriormente las migraciones no figuraban en la agenda de las campañas electorales.

La politización de la situación venezolana ha conllevado también a que gobiernos "amigos" del régimen tiendan a obviar el fenómeno migratorio o incluso a ejercer una política punitiva contra los migrantes venezolanos (Serbin, 2018). Tal ha sido el caso, por ejemplo, de Trinidad y Tobago cuyo gobierno ha deportado por mar a familias y a niños solos, en precarias condiciones, sin seguir procesos ajustados al derecho internacional (HRW, 2020). Algunas de estas embarcaciones han naufragado sin que el gobierno trinitario haya respondido por las vidas de los deportados (HRW, 2020). Otro de los graves problemas relacionado a las islas del Caribe y que tiene que ver con las condiciones de tránsito, es la gran vulnerabilidad, particularmente en niñas y mujeres frente a las redes de tráfico de seres humanos y de trabajo forzado en talleres y fábricas (Serbin, 2018). Esto ha conllevado a una reformulación de la figura del "desaparecido" que en Venezuela se vincula tanto a los ahogamientos por mar como a la desconexión y aislamiento que sufren algunos migrantes cuando son subsumidos por estas redes criminales (López, 2020). Análogos a los que "desparecen" en el mar Caribe, están aquellos "caminantes" migrantes que fallecen por hipotermia en algunas zonas extremas del altiplano andino (France 24, 2021). Muchos también son sometidos a mafias migratorias, sobre todo las vinculadas a los caminos irregulares para pasar de Venezuela a Colombia.

En las antípodas de la criminalización del fenómeno migratorio que hemos expuesto por parte de gobiernos como el de Trinidad y Tobago, es importante destacar el reciente decreto de Estatuto Temporal de Protección para Migrantes en Colombia que regulariza a los migrantes hasta por diez años (ACNUR, 2021a; Riaño, 2021). Se trata de una medida ejemplar que ha tenido lugar precisamente en un país con poca tradición de recepción de inmigrantes y con una larga historia particular de conflictos, desplazados internos y los desplazados hacia Venezuela. Se espera que esta medida pueda servir de ejemplo para otros gobiernos de la región. Por su parte, en marzo de 2021, Joe Biden cumplió su promesa electoral al extender un TPS para 300.000 venezolanos en Estados Unidos, quienes podrán permanecer y trabajar en el país por un período de 18 meses (Sesin, 2021).

\section{¿Diáspora venezolana? Consideraciones teóricas y prácticas}

Una vez situada la situación de la inmigración venezolana, cabe preguntarnos si se trata de una diáspora, y en base a qué hacemos esa evaluación. Esta categorización no implica un esfuerzo menor si consideramos que se ha publicado mucho sobre las diásporas sin que dichos trabajos definan el concepto. Así, el lector queda librado a su imaginación, o se da por sentado que existe consenso sobre los que es una diáspora, o se asume que toda migración constituye una diáspora. 
Faist (2010) afirma que el concepto de diáspora se ha politizado, y a pesar de ser un concepto antiguo, se ha popularizado tanto en la literatura académica como en los discursos públicos. Este autor analiza el concepto de diáspora junto y en comparación al de transnacionalismo, lo que resulta no solo sugestivo, sino también práctico y lógico, ya que la diáspora existe en cuanto fenómeno transnacional, enraizada y vinculada al país de origen y el/los de destino. Por su lado Brubaker (2005) también reconoce el proceso de politización al afirmar que el concepto de diáspora no puede ser usado de forma inocua.

Siguiendo las premisas de Faist (2010), sabemos que en general

los grupos nacionalistas o los gobiernos usan el concepto de diáspora para defender agendas de la construcción de la nación o controlar poblaciones que residen en el exterior. El concepto es invocado para movilizar apoyo hacia una identidad de grupo o algún proyecto político, a veces al servicio de una patria externa, como la protección de las minorías étnicas que viven en otros estados (por ejemplo la protección estatal). Recientemente, incluso los países de origen de la inmigración usan 'diáspora' para incentivar inversiones y promover la lealtad política entre los expatriados exitosos. (2010, p. 11)

Esto ilustra los diversos usos y entendimientos del concepto de diáspora que hacen necesario identificar los elementos que la caracterizan. Para ello optamos nuevamente por el modelo de Faist debido a su doble abordaje en el que considera, por un lado, características o atributos de la diáspora y por el otro, una dimensión temporal sobre su antiguo o nuevo uso. En resumen, los elementos que caracterizan a la diáspora son: a) motivación y/o causa de la dispersión, b) experiencias transfronterizas/transnacionales entre el origen y destino, y c) incorporación o integración de los inmigrantes o minorías en el país de destino. Si bien Faist relaciona la dimensión temporal con el uso antiguo o reciente del concepto, proponemos una comprensión diferente de la dimensión temporal de la diáspora, ya que consideramos que ella es cambiante, por lo que el dinamismo temporal acompaña la propia evolución histórica, así como también espacial/ geográfica de la diáspora, evolucionando y cambiando a lo largo del tiempo.

Asimismo, siguiendo la recomendación de Délano y Gamlen (2014), las diásporas ya no pueden ser vistas como proyectos que buscan mantener intacta una determinada identidad que vaya más allá de la mera dispersión traumática. Por el contrario, deben ser vistas como un indicador de identidades en movimiento. Las diásporas no reflejan entidades sociales fijas, sino que resultan "proyectos en construcción de membresía iniciados por emprendedores tanto en los estados de origen como en el exterior" (2014, p. 44). Por otro lado, y dependiendo de las características de cada diáspora, las agencias gubernamentales en el país de origen pueden desempeñar un rol importante en estimular a grupos a que se piensen a sí mismos como diásporas leales. Sin embargo, como veremos, en el caso de Venezuela, debido a la politización, la lealtad se transforma en oposición al actual régimen como elemento aglutinador. 
Como sugería Faist al relacionar el concepto de diáspora al de trasnacionalismo, éste último resulta útil para contextualizar, describir y entender la diáspora. Siguiendo a Vertovec, el transnacionalismo se refiere a "los múltiples lazos e interacciones que conectan a las personas o instituciones a través de las fronteras de los estados-nación" (1999, p. 447). En la actualidad, el transnacionalismo incluye actores estatales y no estatales en los países de origen y destino, incluidos los propios inmigrantes. Una ventaja que brinda este concepto es que permite transcender el nacionalismo metodológico, es decir, la tendencia académica a enfocar su análisis en el estado-nación como unidad básica de análisis (Wimmer, Glick-Schiller, 2002), dando protagonismo a otros actores, entre ellos los migrantes y sus organizaciones. De este modo, se va más allá de la influencia de los estados. Así, la dupla diáspora/trasnacionalismo resulta una herramienta conceptual que posibilita la comprensión no solo del fenómeno migratorio en sí, sino también facilita un mejor entendimiento de la complejidad de sus actores, contextos, situaciones y su evolución a lo largo del tiempo.

En el caso que nos ocupa, tanto la politización e ideologización como el grado de transnacionalismo y articulación de la migración venezolana son evidentes. Si bien esta migración no constituye un fenómeno totalmente nuevo - ya que se ha dado en mayor o menor medida desde fines de la década de 1990-, en los últimos años la salida de venezolanos y venezolanas del país se ha incrementado de manera exponencial. De cara a este escenario, organizaciones internacionales y regionales como las Naciones Unidas (y sus varias agencias asociadas) y la Organización de Estados Americanos (OEA) hablan de crisis migratoria y humanitaria, a la que, desde marzo de 2020, se agrega la crisis sanitaria. Para entender el actual fenómeno migratorio venezolano, es importante conocer al menos el pasado reciente, ya que la contextualización histórica ayuda a captar la envergadura de lo que está sucediendo.

Hasta hace poco, Venezuela era un país de inmigración, sin embargo desde el inicio del nuevo milenio, se ha transformado en país de emigración. De este modo, dejó de ser la "joya" de América Latina, para comenzar a registrar las primeras olas migratorias hacia otros países. Venezuela recibió inmigrantes europeos, especialmente del sur de Europa hasta casi 1980 y, también, miles de latinoamericanos entre los que se contaron exiliados políticos del Cono Sur, mano de obra calificada asociada a la industria del petróleo y desplazados y refugiados colombianos, entre otros.

Un momento de transición migratoria inicial o punto de inflexión, se produjo en la década de 1980, marcada por la denominada "fuga de cerebros" o talentos (Piñango, 1991; Pellegrino, Calvo, 2001). Sin embargo, un cambio más profundo se comienza a producir con la llegada de Chávez al poder en 1999. Así Páez y Vivas (2017) describen tres olas migratorias que denominan: a. La era Chávez, b. El fin de la era chavista y c. La era Maduro o migración de la desesperación. Asimismo 
y siguiendo esta lógica, desde 2019, tanto la prensa como las organizaciones que trabajan en el terreno hablan de la ola de "caminantes" y de "balseros", ya que ante la desesperación y merma de recursos, los que parten ya no usan los medios de transportes tradicionales (aéreo o terrestre) sino que lo hacen caminando hacia el resto de América Latina, o en botes hacia las islas del Caribe, agravando la situación y el grado de desespero.

Lo cierto es que desde 2014 se registró un aumento exponencial de la vulnerabilidad en Venezuela y de la masificación de la migración. A medida que pasa el tiempo, esto ha afectado también la composición de los flujos, tanto en relación al destino de la emigración como al perfil de clase social de quienes abandonan el país. Mientras que los flujos iniciales se asociaban las clases acaudaladas, personas de negocios y estudiantes internacionales hacia los Estados Unidos y Europa, en una segunda etapa se produce una diversificación que incluye las clases medias que migran a destinos similares y también a otros países como Colombia, Panamá y la República Dominicana. En la tercera etapa, que coincide con el deterioro generalizado de la situación en Venezuela, la muerte de Chávez y el aumento de la violencia, los venezolanos que salen del país son personas de diferentes edades, clases sociales, niveles educativos y profesiones (Freitez, 2011; Freier, Parent, 2018). Estas variaciones están determinadas por factores como la distancia de Venezuela con el país de destino, así como también por las políticas migratorias y de integración en dichos países que permiten (o no) su entrada y, posteriormente, facilitan o dificultan su inserción.

\section{Diáspora venezolana en Argentina, Estados Unidos y Portugal}

Teniendo en cuenta los elementos que Faist identifica en relación a las diásporas, ofrecemos a continuación una reflexión preliminar basada en el trabajo de campo realizado entre 2018 y 2020, en Argentina, los Estados Unidos de América (Florida) y Portugal. Dicho trabajo consistió en entrevistas semi-estructuradas a inmigrantes venezolanos, observación participante y entrevistas a informantes clave. Los tres países de destino poseen diferentes políticas migratorias y de integración (o falta de ellas) y vínculos con la diáspora venezolana. A su vez, ninguno de esos países es limítrofe con Venezuela, lo que podría describirlos como destinos elegidos o buscados. La Tabla 1 resume algunas características de los destinos de la diáspora incluyendo las políticas migratorias que pueden actuar como elemento de atracción y facilitación (o complicación) de la residencia.

Sin obviar las diferencias que presentan estos tres destinos de la diáspora venezolana, las narrativas de los migrantes identificaron un conjunto de situaciones comunes que marcaban sus vidas antes de migrar. Salvo las personas que emigraron en olas anteriores ("fuga de cerebros" hasta el fin de la era chavista), quienes lo hicieron desde 2014 hablaron de motivos semejantes para salir del país: escasez de alimentos y hambre, falta de medicamentos y acceso a la salud, paulatina 
desarticulación del sistema educativo (los profesores universitarios habían ido desertando de a poco y ya no quedaban suficientes para seguir la carrera), escasez de electricidad, agua e internet y cortes de otros servicios.

Tabla 1 - Características de los Destinos de la Diáspora Venezolana

\begin{tabular}{|c|c|c|c|c|}
\hline $\begin{array}{l}\text { País de } \\
\text { destino }\end{array}$ & $\begin{array}{l}\text { Justificación del } \\
\text { destino }\end{array}$ & $\begin{array}{l}\text { Documentos de } \\
\text { viaje }\end{array}$ & Políticas migratorias & Resultado \\
\hline Argentina & $\begin{array}{l}\text { Lazos familiares o de } \\
\text { amigos }\end{array}$ & $\begin{array}{l}\text { Flexibilidad en } \\
\text { la aceptación de } \\
\text { documentos }\end{array}$ & $\begin{array}{c}\text { Flexibilidad migratoria; } \\
\text { Menor discriminación; } \\
\text { Acceso a derechos }\end{array}$ & \multirow{3}{*}{ 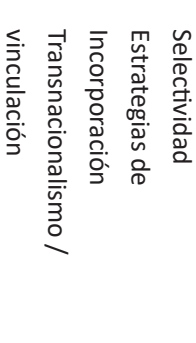 } \\
\hline Portugal & $\begin{array}{l}\text { Lazos familiares luso- } \\
\text { descendientes }\end{array}$ & Pasaporte & Acceso a nacionalidad & \\
\hline $\begin{array}{l}\text { Estados } \\
\text { Unidos }\end{array}$ & $\begin{array}{l}\text { Deseabilidad del } \\
\text { destino; sueño } \\
\text { americano; lazos } \\
\text { familiares }\end{array}$ & Pasaporte y visa & $\begin{array}{c}\text { Asilo; } \\
\text { Protección } \\
\text { Internacional }\end{array}$ & \\
\hline
\end{tabular}

Fuente: Elaboración propia.

En pocas palabras, estos motivos ilustran el desentendimiento del estado venezolano para con sus ciudadanos. Por otro lado, todos los entrevistados mencionaron experiencias de persecución política y/o el aumento desmedido de la violencia en la sociedad ya sea por robos, secuestros, atentados y muertes de familiares y/o amigos, incluyendo violencia ejercida o facilitada por el estado. Así, la presencia del estado como máquina represiva, por un lado, y su ausencia como prestador de servicios por el otro, interactúan como factores de expulsión. Esta situación se ve agravada por el hecho de que el estado no admite su responsabilidad en el éxodo migratorio, ni provee a sus ciudadanos documentos básicos de viaje que les permita entrar y salir del país, fomentando huidas irregulares que no sólo dificultan la entrada y circulación en otros países, sino que también elevan el riesgo de la integridad física de los migrantes.

Mientras en el interior de Venezuela la violencia y desprotección actúan como disparadores de la emigración llevando a la dispersión de sus ciudadanos, en el exterior estos disparadores ayudan a los migrantes a identificar elementos comunes o de cohesión, compartiendo no solo su sentido de pertenencia e identidad nacional, sino también identificando objetivos en común: el fin del régimen, la ayuda y asistencia a familiares y amigos aun en el país, la creación de redes de ayuda mutua, la colaboración y asistencia en la emergencia migratoria.

Un factor importante a considerar al momento de evaluar el nivel de atracción hacia ciertos países particulares, es el de las políticas existentes o la falta de ellas. Los y las venezolanas entrevistadas en Argentina, los Estados Unidos y Portugal, sin excepción, barajaron una serie de posibles destinos migratorios, y consideraron no sólo la existencia de redes en cada destino, sino también la posibilidad de éxito debido a la situación económica, sus calificaciones, la apertura de la sociedad de 
destino, y la existencia/acceso a documentos de viaje como el pasaporte y/o la visa, entre otros. En este sentido, el país de destino pasa por un proceso de selectividad exhaustivo y nos permite identificar las siguientes generalizaciones:

1. La inmigración venezolana en Argentina es muy reciente, y si bien es un flujo nuevo, es posible identificar conexiones anteriores entre ambos países, ya que durante la dictadura argentina de 1976 a 1983, aproximadamente 22.000 argentinos emigraron a Venezuela. En décadas siguientes, también lo hicieron ingenieros que trabajaban en la industria del petróleo (Biderbost, Nuñez, 2018). Sin embargo, la activación de estas viejas redes no es suficientes para explicar la preferencia hacia Argentina, y las narrativas de los venezolanos sustentan su preferencia hacia ese país en base a los derechos a los cuales los inmigrantes tienen acceso. La legislación migratoria argentina actual reconoce el migrar como un derecho humano, y garantiza el derecho a la educación y a la salud. De hecho, permite el acceso a la educación superior a través del sistema de universidades nacionales, el cual es gratuito. Además de contar con estos derechos, muchos entrevistados señalaron que eligieron Argentina porque aunque su situación económica no fuese la más favorable, sentían simpatía por el perfil político del gobierno (en ese momento representado por el presidente Mauricio Macri, apoyado por una coalición de centro-derecha; en la actualidad eso ha cambiado), y porque la discriminación era percibida como menor en comparación con otros países donde las experiencias xenofóbicas se habían hecho virales como en Perú, Ecuador y Brasil. La flexibilidad y apertura del sistema legal argentino llevaron a que los pedidos de asilo fuesen muy reducidos (casi innecesarios ya que la via migratoria normal era más ventajosa), a pesar de que el Poder Ejecutivo otorgó a los venezolanos un estatuto especial que equiparaba su situación a la de los refugiados sirios. Esto se tradujo en una mayor flexibilidad documental y burocrática. Un reciente informe elaborado por la Representación Diplomática de Venezuela en la Argentina afirma que "desde el 2016 se puede apreciar como Argentina pasó a ser una de las mejores opciones dentro del continente como un lugar de residencia para los venezolanos" (s/d). En los últimos años, los venezolanos representan la primera nacionalidad en solicitar residencia, casi duplicando el número de pedidos de los paraguayos, la segunda nacionalidad, según los datos de la Dirección Nacional de Migraciones.

2. A diferencia de Argentina y Portugal, salvo las excepciones de las personas que atraviesan la frontera sur ${ }^{5}$, los Estados Unidos exige pasaportes válidos y visas vigentes para poder ingresar al país, lo que implica una mayor selectividad ${ }^{6}$. Por otro lado, la presencia venezolana en este país es más antigua, ligada a las clases altas y medias y a la "fuga de cerebros". Esta migración más establecida tanto financiera como políticamente, está articulando redes de apoyo a muchos

5 Con el paso del tiempo se ha vuelto más común que los venezolanos entren por la frontera sur como indocumentados.

6 La selectividad la determinan sobre todo los documentos de viaje (pasaporte, visa, recursos económicos que se puedan pedir al momento de entrada). 
de los venezolanos recién llegados. Éstos por su parte, una vez que ingresan al país, solicitan asilo para asegurar su permanencia legal. Al hacerlo, su situación migratoria queda pendiente y reciben autorización para trabajar mientras esperan por la entrevista. Este proceso demora incluso varios años, por lo que su estatuto migratorio los mantiene en un limbo durante mucho tiempo. Con la excepción de los que se beneficiaron de la residencia por lotería, todos los venezolanos consultados esperaban la entrevista. Más recientemente, con el decreto aprobado por el presidente Biden en marzo de 2021, otorgando a los venezolanos el estatus de protección temporal por 18 meses, no sólo podrán continuar los pedidos de asilo, sino que ya se están incrementando significativamente los de protección temporaria. Se trata de una medida humanitaria que podría beneficiar a más de 300 mil venezolanos que ya se encuentran en Estados Unidos.

3. La inmigración venezolana en Portugal es principalmente una consecuencia de la emigración portuguesa de retorno, por la cual ciudadanos portugueses y/o sus descendientes, migran al país de origen. Lo hacen porque poseen documentos portugueses o pueden obtenerlos con facilidad. Quienes no tienen dicha documentación, esperan poder hacerlo o beneficiarse de las políticas de inmigración portuguesas que, comparativamente con otros países de la Unión Europea, son más abiertas y permiten la regularización (Padilla, França, 2020; Padilla, Ortiz, 2012, 2014), aunque no existan políticas especiales para los venezolanos, como en Colombia y Estados Unidos, o incluso Argentina. En Portugal, los venezolanos ocupan el segundo lugar entre los latinoamericanos, después de los brasileños, como grupo nacional residente más numeroso y, desde 2015, las cifras han crecido intensamente. Prueba de los vínculos estrechos entre Portugal y Venezuela es la preponderancia que los venezolanos tienen en el archipiélago de Madeira, lugar de proveniencia de una parte significativa de la emigración portuguesa a Venezuela, y tierra en la que sus descendientes se han establecido. Una amplia faja de la población venezolana tiene nacionalidad portuguesa o está tramitando la reunificación. La presencia venezolana se hace evidente en las calles donde transeúntes hablan español, en los negocios que venden comida venezolana y en el gentilicio con el que se los conoce a los venezolanos en la isla: "los mira, mira".

\section{La trasnacionalidad de los venezolanos: ¿una diáspora en construcción?}

La pregunta ante el escenario presentado es si los inmigrantes venezolanos son y actúan como una diáspora. Si bien es temprano para realizar una evaluación sistemática de la situación, reflexiones sobre la realidad transnacional que viven los venezolanos como inmigrantes y/o refugiados en países como Argentina, Estados Unidos y Portugal, sumado a las de la situación en el país de origen, nos lleva a pensar que los venezolanos son una diáspora en vías de institucionalización 
y consolidación. Sustentamos esto en dos factores principales que actúan como elementos unificadores, que a su vez pueden repercutir de diferentes maneras en el proceso de formación y consolidación de la diáspora.

Por un lado, el escenario dominante del país de origen (violencia, corrupción, falta de recursos y la ausencia del estado de derecho, entre otros), sirve como elemento unificador de aquellos y aquellas que se encuentran en el exterior, a pesar de las diferencias de clase social, género, pertenencia étnica o racial e inclusive ideológicas.

Por otro lado, la necesidad de ayudarse y apoyarse en los nuevos contextos migratorios, también funciona como elemento de cohesión en el exterior. Venezolanos y venezolanas pioneras abrieron el camino, prestaron apoyo y brindaron el capital social desarrollado con años de anterioridad, para asistir inicialmente a los recién llegados, aunque aun continúa predominando la informalidad. La necesidad de apoyarse colectivamente ha llevado a estos inmigrantes a mantener una movilización constante. Los venezolanos y venezolanas se organizan, ya sea formalmente en asociaciones y/o, sobre todo, en grupos informales (de WhatsApp, Facebook, Instagram, etc.) que crecen día a día. Integran varios de estos grupos de manera activa, no solo dentro de los países de destino, sino también afuera, más allá del país de origen. Esto se debe a que muchas veces las familias y amistades ya llevan una vida trasnacionalizada. Se trata generalmente de estrategias de migración planificada para distribuir el riesgo y optimizar la sobrevivencia fuera del país de origen. De esta manera, asistimos a formas de vida trasnacionales que en conexión con múltiples países y de manera simultánea permiten a los inmigrantes permanecer informados sobre lo que sucede en Venezuela y también estar conectados con sus familiares, amigos y colegas en otros lugares.

A estos vínculos en redes hay que agregar que la mayoría envía dinero (pocas, medianas o cuantiosas remesas dependiendo de la situación del inmigrante), y/u otro tipo de recursos (cajas con medicamentos, elementos de primera necesidad) de forma regular a Venezuela. La propia desarticulación del estado venezolano y la condición de embargo internacional, ha llevado a que se desarrollen sistemas paralelos e informales de remesas, tramitación y envío de documentos hacia adentro y hacia afuera, actuando también como elementos aglutinadores.

Todos estos fenómenos de vinculación constante entre distintos países como Argentina, los Estados Unidos y Portugal, a partir de la experiencia común de la crisis venezolana, dan cuenta de un éxodo masivo que en su trasnaciolización ya no puede ser estudiado bajo los parámetros estrechos del estado nacional. En sus múltiples y simultáneas articulaciones a lo largo del mundo, sugerimos que la migración venezolana es una diáspora en construcción. En los próximos años, restará por ver y analizar cuáles serán las consecuencias de este proceso de diasporización acelerada en la reformulación de una identidad común que ya no será la misma inicial del país de origen. 


\section{Referencias bibliográficas}

ACNUR. ACNUR y OIM aplauden la decisión de Colombia de regularizar a personas refugiadas y migrantes de Venezuela. UNHCR/ACNUR, La Agencia de la ONU para los Refugiados, 2021a. Disponible en: <https://www.acnur.org/noticias/ press/2021/2/6021acc44/acnur-y-oim-aplauden-la-decision-de-colombia-deregularizar-a-personas.html $>$.

ACNUR. Situación en Venezuela. UNHCR/ACNUR, La Agencia de la ONU para los Refugiados, 2021b. Disponible en: < https://mww.acnur.org/situacion-en-venezuela.html>.

BIDERBOST, Pablo; NUÑEZ, María Elisa. Del río de la Plata al Orinoco y viceversa. Patrones y flujos migratorios entre Argentina y Venezuela. In: KOECHLIN, José; EGUREN, Joaquín (eds.). El éxodo venezolano. Entre el exilio y la emigración. Lima: Konrad Adenauer Stiftung; Universidad Antonio Ruiz de Montoya, 2018, p. 135-166.

BRUBAKER, Rogers. The 'diaspora' diaspora. Ethnic and Racial Studies, v. 28, n. 1, p. 1-19, 2005.

CARRASCO, Daniela. Claudia López vuelve a criminalizar a los venezolanos en Bogotá. El Pitazo, 09.09.2020. Disponible en: < https://elpitazo.net/migracion/ claudia-lopez-vuelve-a-criminalizar-a-venezolanos-en-bogota/> .

CELAG. Informe de la ONU sobre el impacto de las sanciones a Venezuela. Celag. org, 2021. Disponible en: <https://www.celag.org/informe-de-la-onu-sobre-elimpacto-de-las-sanciones-a-venezuela/> .

DEKOCKER, Katrien. La comunidad venezolana en España. De una estrategia migratoria de reproducción social a una creciente pobreza emergente. In: KOECHLIN, José; EGUREN, Joaquín (eds.). El éxodo venezolano. Entre el exilio y la emigración. Lima: Konrad Adenauer Stiftung; Universidad Antonio Ruiz de Montoya, 2018, p. 293-336.

DÉLANO, Alexandra; GAMLEN, Alan. Comparing and theorizing state-diaspora relations. Political Geography, v. 41, p. 43-53, 2014.

DÍAZ, Jefferson. La xenofobia contra los venezolanos protagoniza las elecciones en Ecuador. Cinco8, 01.02.2021. Disponible en: <https://www.cinco8.com/ periodismo/la-xenofobia-contra-los-venezolanos-protagoniza-las-elecciones-enecuador/ $>$.

EDSON LOUIDOR, Wooldy. La migración forzada de Venezuela a Colombia (20152018): de una revisión documental a los esbozos de un análisis coyuntural y estructural. In: KOECHLIN, José; EGUREN, Joaquín (eds.). El éxodo venezolano. Entre el exilio y la emigración. Lima: Konrad Adenauer Stiftung; Universidad Antonio Ruiz de Montoya, 2018, p. 21-46.

Encovi. Encuesta Nacional de Condiciones de Vida. Encovi, Universidad Católica Andrés Bello/UCAB 2014-2018, 2019. Disponible en: <https://www.proyectoencovi.com/>.

FAIST, Thomas. Diaspora and transnationalism: What kind of dance partners? In: BAUBÖCK, Rainer; FAIST, Thomas (eds.). Diaspora and Transnationalism. Concepts, Theories and Methods. Amsterdam: Amsterdam University Press, 2010.

France 24. Dos inmigrantes mueren tras cruzar irregularmente la frontera Chile-Bolivia. France 24, 21.03.2021. Disponible en: <https://www.france24.com/es/minuto-aminuto/20210203-dos-inmigrantes-mueren-tras-cruzar-irregularmente-la-fronterachile-bolivia $>$. 
FREIER, Luisa F.; PARENT, Nicolas. The Regional Response to the Venezuelan Exodus. Current History, v. 118, p. 56-61, 2019.

FREITEZ, Anitza. Crisis humanitaria y migración forzada desde Venezuela. In: GANDINI, Luciana; LOZANO ASCENCIO, Fernando; PRIETO, Victoria (coords.). Crisis y migración de población venezolana. Entre la desprotección y la seguridad jurídica en Latinoamérica. Ciudad de México: Universidad Autónoma de México, 2019, p. 33-58.

FREITEZ, Anitza. Prólogo. In: KOECHLIN, José; EGUREN, Joaquín (eds.). El éxodo venezolano. Entre el exilio y la emigración. Lima: Konrad Adenauer Stiftung; Universidad Antonio Ruiz de Montoya, 2018, p. 9-14.

FREITEZ, Anitza. La emigración desde Venezuela durante la última década. Temas de Coyuntura, v. 63, p. 11-38, 2011.

GANDINI, Luciana; LOZANO ASCENCIO, Fernando; PRIETO, Victoria. "Introducción" y "El éxodo venezolano: migración en contextos de crisis y respuestas de los países latinoamericanos". In: GANDINI, Luciana; LOZANO ASCENCIO, Fernando; PRIETO, Victoria (coords.). Crisis y migración de población venezolana. Entre la desprotección y la seguridad jurídica en Latinoamérica. Ciudad de México: Universidad Autónoma de México, 2019, p. 1-8; 9-32.

HRW. The Deportation of Venezuelan Kids Should Stop. Human Rights Watch, 18.12.2020. Disponible en: <https://www.hrw.org/news/2021/02/03/deportationvenezuelan-kids-should-stop $>$.

HRW. Venezuela's Humanitarian Emergency. Human Rights Watch, 04.04.2019. Disponible en: <https://www.hrw.org/report/2019/04/04/venezuelas-humanitarianemergency/large-scale-un-response-needed-address-health $>$.

IOM. Venezuelan Refugee and Migrant Crisis. IOM UN Migration, 2018. Disponible en: <https://www.iom.int/venezuela-refugee-and-migrant-crisis>.

KRITZ, Mary. The Impact of International Migration on Venezuelan Demographic and Social Structure. International Migration Review, v. 9, n. 4, p. 513-543, 1975.

LÓPEZ MAYA, Margarita. Pandemia y control totalitario. In: MARTí I PUIG, Salvador; ALCÁNTARA SÁEZ, Manual (eds.). Política y crisis en América Latina. Impacto de la Covid-19. Barcelona: Cátedra de Cultura Jurídica-Marcial Pons, 2020, p. 349-364.

LÓPEZ, Magdalena. Figura do 'desaparecido' é ressignificada na Venezuela. Folha de São Paulo, 29.12.2020. Disponible en: < https://www1.folha.uol.com.br/ mundo/2020/12/figura-do-desaparecido-e-resignificada-na-venezuela.shtml > .

LLORENTE, Analía. Migración en Chile. "Me sentí como un delincuente": el testimonio de uno de los venezolanos deportados por el gobierno chileno. BBC News Mundo, 14.02.2021. Disponible en: <https://www.bbc.com/mundo/noticias-americalatina-56051174>.

MÉNDEZ URICH, Luís. Chile deporta a más de 100 inmigrantes entre venezolanos y colombianos. France 24, 10.02.2021. Disponible en: < https://www.france24.com/ es/am\%C3\%A9rica-latina/20210210-chile-venezolanos-inmigrantes-deportacioncrisis-venezuel>.

OAS/CIDH. CIDH adopta resolución sobre migración forzada de personas venezolanas. OAS, 14.03.2018. Disponible en: <https://www.oas.org/es/cidh/prensa/comunica dos/2018/048.asp >. 
PADILLA, Beatriz; FRANÇA, Thais. Tres décadas después... Evolución de las políticas de incorporación de inmigrantes en Portugal: Una nueva lectura. Politica Globalidad y Ciudadanía, v. 6. n. 11, p. 171-202, 2020.

PADILLA, Beatriz; ORTIZ, Alejandra. Ciudadanía transnacional: latinoamericanos en Portugal. Revista CIDOB d'Afers Internacionals, n. 106/107, p. 30-59, 2014.

PADILLA, Beatriz; ORTIZ, Alejandra. Fluxos migratórios em Portugal: do boom migratório à desaceleração no contexto de crise. Balanço e desafios. REMHU, Revista Interdisciplinar da Mobilidade Humana, v. XX, n. 39, p. 159-184, 2012.

PÁEZ, Tomas; VIVAS, Leonardo. The Venezuelan Diaspora: Another Impending Crisis?. Freedom House Report, 2017. Disponible en: <https://www.researchgate.net/ publication/317099053_The_Venezue-lan_Diaspora_Another_Impending_Crisis $>$.

PELLEGRINO, Adela; CALVO, Juan José. ¿Drenaje o éxodo? Reflexiones sobre la migración calificada. Documento de trabajo n. 12. Montevideo, Uruguay: Rectorado de la Universidad de la República, 2001.

PIÑANGO, Ramon. La fuga como opción de carrera ante las limitaciones de las organizaciones venezolanas para aprovechar el talento. In: GARBI, Esmeralda (comp.). La Fuga de Talento en Venezuela. Caracas, Venezuela: IESA, 2021, p. 7-26.

RIAÑO, Julieth. El Estatuto de Protección Temporal, un alivio para los venezolanos en Colombia. France 24, 16.02.2021. Disponible en: < https://www.france24.com/ es/programas/migrantes/20210216-estatuto-proteccion-temporal-venezolanoscolombia $>$.

ROJAS, Nastassja. La crisis migratoria venezolana. Latinoamérica 21, 14.02.2021. Disponible en: < https://latinoamerica21.com/podcast/la-crisis-migratoria-venezo lana/ ?utm_source $=$ rss\&utm_medium $=$ rss\&utm_campaign $=$ la-crisis-migratoria-venezolana $>$.

SERBIN PONT, Andrei. La crisis humanitaria en Venezuela y su impacto regional: migración, seguridad y multilateralismo. Pensamiento Propio, v. 47, p. 129-158, 2018.

SESIN, Carmen. Senate Democrats introduce legislation to grant Temporary Protected Status to Venezuelans. NBC News, 25.01.2021. Disponible en: < https:// www.nbcnews.com/news/latino/senate-democrats-introduce-legislation-granttemporary-protected-status-venezuelans-n1255604>.

SMOLANSKY, David. Cifra de migrantes y refugiados venezolanos podía superar a la de Siria en 2021. Todosahora, 2021. Disponible en: < https://www.todosahora. com/venezuela/oea-cifra-de-migrantes-y-refugiados-venezolanos-podria-superara-la-de-siria-en-2021/>.

VERTOVEC, Steven. Conceiving and researching transnationalism. Ethnic and Racial Studies, v. 22, n. 2, p. 447-462, 1999.

WIMMER, Andreas; GLICK-SCHILLER, Nina. Methodological nationalism and beyond: nation-estate building, migration and the social sciences. Global Networks, v. 2, n. 4, p. 301-334, 2002.

WOLA. Venezuela's Complex Humanitarian Crisis: Humanitarian Response, Challenges for Civil Society. WOLA - Advocay for Human Rights in the Americas, 24.11.2020. Disponible en: <https://www.wola.org/analysis/venezuelas-complex-humanitariancrisis/ $>$. 